\title{
Fenofibrate: direct attenuating effects on tumor growth
}

\author{
Shailendra Kapoor \\ University of Illinois at Chicago, Chicago, IL, USA
}

The recent article by Liu et al. [1] provided for highly stimulating and interesting reading. Interestingly, recent data suggests that fenofibrate may directly attenuate tumor growth in a number of systemic malignancies.

For instance, fenofibrate is of benefit in mitigating tumor progression in prostatic malignancies. It has a negative impact on intercellular coupling via gap junctions between the cancerous cells [2]. Cancer cell motility is significantly attenuated. The ultimate result is marked inhibition of tumor growth. Similar benefit has been noted in endometrial malignancies. Fenofibrate administration results in $G_{1} / S$ phase arrest. Cyclin D1 expression is significantly decreased. It also results in accentuated intra-tumoral apoptosis. The anti-neoplastic effects of fenofibrate are especially more pronounced when used in conjunction with retinoic acid [3].

Inhibition of tumor growth is also seen in hepatocellular malignancies secondary to the administration of fenofibrate. Accentuated $G_{1}$ phase arrest is typically seen. It mediates these anti-neoplastic effects by virtue of attenuation of Akt activation within the cancerous cells. "C-terminal modulator" protein levels are up-regulated as are p27 levels [4]. E2F1expression is down-regulated. Interestingly, these anti-neoplastic effects are independent of the peroxisome proliferator-activated receptor $\alpha$ (PPAR $\alpha)$ inhibition. Similar effects are seen in oral squamous cell carcinomas. It especially affects carcinogenesis in oral tissue thus inhibiting the formation of oral malignancies. It mediates this role, in part, by down-regulating cyclooxygenase- 2 expression in oral squamous cell carcinomas [5]. A negative impact on "epidermal growth factor receptor" expression in oral squamous cell carcinomas is also seen simultaneously.

It is obvious from the above examples that fenofibrate has significant anti-neoplastic effects. Further studies are needed to fully harness these anti-tumor effects.

\section{References}

1. Liu $X$, Jang $S S, A n Z$, et al. Fenofibrate decreases radiation sensitivity via peroxisome proliferator-activated receptor $\alpha$-mediated superoxide dismutase induction in HeLa cells. Radiat Oncol J 2012;30:88-95.

2. Wybieralska E, Szpak K, Gorecki A, et al. Fenofibrate attenuates contact-stimulated cell motility and gap junctional coupling in DU-145 human prostate cancer cell populations. Oncol Rep 2011;26:447-53.

3. Saidi SA, Holland CM, Charnock-Jones DS, Smith SK. In vitro and in vivo effects of the PPAR-alpha agonists fenofibrate and retinoic acid in endometrial cancer. Mol Cancer 2006;5:13.

4. Yamasaki D, Kawabe $N$, Nakamura $H$, et al. Fenofibrate suppresses growth of the human hepatocellular carcinoma cell via PPAR $\alpha$-independent mechanisms. Eur J Cell Biol 2011; 90:657-64.

5. Chang NW, Tsai MH, Lin C, et al. Fenofibrate exhibits a high potential to suppress the formation of squamous cell carcinoma in an oral-specific 4-nitroquinoline 1-oxide/arecoline mouse model. Biochim Biophys Acta 2011;1812:558-64.

\footnotetext{
Received 13 February 2013, Accepted 20 February 2013.

Correspondence: Shailendra Kapoor, University of Illinois at Chicago, Chicago, IL, USA. Tel: +1-865-607-1014, Fax: +1-865657-6767, E-mail: shailendrakapoor@yahoo.com

(c) This is an Open Access article distributed under the terms of the Creative Commons Attribution Non-Commercial License (http://creativecommons.org/ licenses/by-nc/3.0/) which permits unrestricted non-commercial use, distribution, and reproduction in any medium, provided the original work is properly cited.
} 